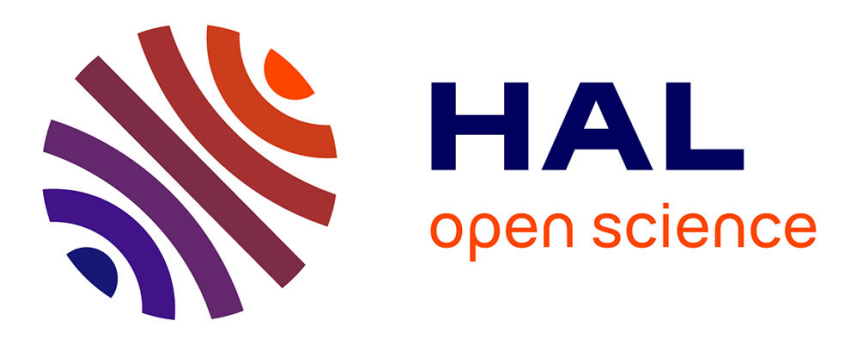

\title{
Numerical Evaluation of Earthquake Settlements of Road Embankments and Its Mitigation by Preloading
}

Fernando Lopez-Caballero, Arézou Modaressi-Farahmand-Razavi, Constantine A. Stamatopoulos

\section{- To cite this version:}

Fernando Lopez-Caballero, Arézou Modaressi-Farahmand-Razavi, Constantine A. Stamatopoulos. Numerical Evaluation of Earthquake Settlements of Road Embankments and Its Mitigation by Preloading. International Journal of Geomechanics, 2016, 16 (5), pp.C4015006. 10.1061/(ASCE)GM.1943-5622.0000593 . hal-01186317

\section{HAL Id: hal-01186317 \\ https://hal.science/hal-01186317}

Submitted on 12 Mar 2020

HAL is a multi-disciplinary open access archive for the deposit and dissemination of scientific research documents, whether they are published or not. The documents may come from teaching and research institutions in France or abroad, or from public or private research centers.
L'archive ouverte pluridisciplinaire HAL, est destinée au dépôt et à la diffusion de documents scientifiques de niveau recherche, publiés ou non, émanant des établissements d'enseignement et de recherche français ou étrangers, des laboratoires publics ou privés. 


\section{INTRODUCTION}

\footnotetext{
${ }^{1}$ MSS-Mat CNRS UMR 8579,Ecole Centrale Paris, Grande Voie des Vignes, 92290 Châtenay-Malabry, France. E-mail: fernando.lopez-caballero@ecp.fr

${ }^{2}$ MSS-Mat CNRS UMR 8579,Ecole Centrale Paris, Grande Voie des Vignes, 92290 Châtenay-Malabry, France. E-mail: arezou.modaressi@ecp.fr

${ }^{3}$ Partner, Stamatopoulos and Associates Co; Instructor, Hellenic Open University; 5 Isavron str, Athens, 11471, Greece. E-mail: k.stam@saa-geotech.gr
} 
Geotechnical structures such as river dikes, highway embankments, and earth dams founded on saturated loose sandy ground have been frequently damaged during past major earthquakes (e.g. the 1964 Niigata Earthquake; the 1989 Loma Prieta Earthquake; the 1993 Kushiro-oki Earthquake; the 1995 Hyogoken-Nanbu Earthquake and the 2011 off the Pacific Coast of Tohoku earthquake among others). Failures of the Kushiro river embankments, Japan (Sasaki et al. 1995), the Shiribeshi-Toshibetsu river embankments, Japan (Kaneko et al. 1995) and the Rimnio Bridge embankment, Grevena, Greece (Tika and Pitilakis 1999) are typical examples. This damage was usually due to liquefaction-induced ground deformations of the embankment and/or foundation sandy ground (Matsuo 1996; Adalier et al. 1998; Unjoh et al. 2012; Okamura et al. 2013). According to Youd (1993) and Marcuson et al. (1996) among others, lateral soil deformations ("lateral spreading") due to cyclic loading have proven to be the most pervasive type of liquefaction-induced ground failure. The amount of lateral displacement typically ranges from a few centimetres to several metres.

In practice, in order to prevent the damage effects of earthquake induced liquefaction in engineering structures, the countermeasure methods such as gravel drains, soil densification, solidification and inclusions or confinement walls among others are used. Such methods are studied by several authors via centrifuge tests (Liu and Dobry 1997; Adalier et al. 1998; Brennan and Madabhushi 2002; Elgamal et al. 2002; Dashti et al. 2010b; Mitrani and Madabhushi 2012) or numerically (Elgamal et al. 2002; Elgamal et al. 2005; López-Querol and Blázquez 2006; Nishimura and Shimizu 2008; Lu et al. 2011; Bradley et al. 2013; Lopez-Caballero and Modaressi-Farahmand-Razavi 2013; Xu et al. 2013). The principal conclusion of these works is that the efficiency of each solution depends on characteristics of the input signal and the properties of the soil.

Preloading is a temporary loading, usually an embankment, applied at a construction site to improve subsurface soils. For construction sites where sandy layers are predominant, experience has illustrated that about three weeks suffice for soil improvement to take place. The method is frequently used to improve bad soil conditions and make them sustain large 
static loads (Stamatopoulos and Kotzias 1985; Petridis et al. 2000). Surcharging the site increases the liquefaction strength of soil foundation and reduces the development of excess pore pressure. In addition, an increase in lateral stress is obtained due to the modification of coefficient of earth pressure at rest $\left(k_{o}\right)$ in the improved soil. The increase in horizontal stress and liquefaction cyclic strength by preloading has been studied and verified by both laboratory tests (Ishihara and Okada 1982; Wichtmann et al. 2005; Bouferra et al. 2007; Porcino et al. 2009; Liu and Xu 2013) and elaborate field tests (Stamatopoulos et al. 2005; Raptakis 2013; Stamatopoulos et al. 2013).

Previous works have used numerical methods to study the response of both liquefiable and improved (i.e. densified) soil profiles and their effects on the structures or dams response (Elgamal et al. 2002; Adalier and Aydingun 2003; Elgamal et al. 2005; Shahir and Pak 2010). In general, most of those numerical models are related to centrifuge modelling test results. Those researches were mainly focused on the effect of a dense region representing the improved method and placed underneath the structure on the settlement induced by soil liquefaction. Those compacted regions were modelled with constitutive model parameters calibrated for a denser soil. On the contrary, to investigate these issues, in this study attention is given to the construction phase of the preloading embankment. The construction and demolition of the preload embankment (i.e construction technique used in this countermeasure method) is simulated and the effects of this loading history on the seismic response of the soil profile are assessed.

The aim of this work is to assess numerically the efficiency of the soil densification using preloading techniques on mitigating excessive seismic ground settlements of road embankments on liquefiable sandy profiles. The numerical results of parametric studies performed to compare the dynamical response of the road embankment at the end of shaking for the cases with and without mitigation method are discussed.

First of all, a description of the used advanced constitutive model is provided. The following section is concerned with the relevant aspects of the numerical model, namely, the 
geometry of the road embankment, the boundary conditions, the simulation of the improvement method and the characteristics of the input ground motions. Then, the elastoplastic constitutive model is calibrated by simulating a series of laboratory cyclic tests. In addition, the model's ability to simulate the effect of preloading on the resistance to the sands liquefaction has been assessed. Finally, a comparison of the performance of the road embankment with and without the improvement method is presented.

\section{SOIL CONSTITUTIVE MODEL}

The elastoplastic multi-mechanism model developed at Ecole Centrale Paris, known as ECP model (Aubry et al. 1982; Hujeux 1985) is used to represent the soil behaviour. This model can take into account the soil behaviour in a large range of deformations. The model is written in terms of effective stress. The representation of all irreversible phenomena is made by four coupled elementary plastic mechanisms: three plane-strain deviatoric plastic deformation mechanisms in three orthogonal planes and an isotropic one. The model uses a Coulomb-type failure criterion and the critical state concept. The evolution of hardening is based on the plastic strain (deviatoric and volumetric strain for the deviatoric mechanisms and volumetric strain for the isotropic one). To take into account the cyclic behaviour a kinematical hardening based on the state variables at the last load reversal is used. The soil behaviour is decomposed into pseudo-elastic, hysteretic and mobilized domains. Refer to Aubry et al. (1982), Hujeux (1985), Lopez-Caballero and Modaressi-Farahmand-Razavi (2008) among others for further details about the ECP model. For the sake of brevity only some model definitions are given in what follows.

Adopting the soil mechanics sign convention (compression positive), the deviatoric primary yield surface of the $k$ plane in the ECP soil constitutive model is given by:

$$
f_{k}\left(\sigma, \varepsilon_{v}^{p}, r_{k}\right)=q_{k}-\sin \phi_{p p}^{\prime} \cdot p_{k}^{\prime} \cdot F_{k} \cdot r_{k}
$$

where, $p_{k}^{\prime}$ and $q_{k}$ are the mean and deviatoric values of stress tensors, $\phi_{p p}^{\prime}$ is the friction angle 
at the critical state, the function $F_{k}$ permits to control the isotropic hardening associated with the plastic volumetric strain, whereas $r_{k}$ accounts for the isotropic hardening generated by plastic shearing. They represent progressive friction mobilization in the soil and their product reaches unity at perfect plasticity. Therefore, in order to provide for any state a direct measure of "distance to reach the critical state" $\left(r_{k}\right)$ and based upon the used elastoplastic model, it is possible to define an apparent friction angle $\left(\phi_{a p t}^{\prime}\right)$ by:

$$
\begin{aligned}
\sin \phi_{a p t}^{\prime} & =\frac{q_{k}}{p_{k}^{\prime} \cdot F_{k}} \\
r_{k} & =\frac{\sin \phi_{a p t}^{\prime}}{\sin \phi_{p p}^{\prime}}
\end{aligned}
$$

The parameters of the ECP model concern both the elastic and plastic behaviour of the soil and they are separated into two categories: those that can be directly measured from either in-situ or laboratory test results and those which, cannot be directly measured (Table $1)$.

\section{NUMERICAL MODEL}

For the purpose of studying numerically the effect of soil preloading technique on the improvement of liquefiable sandy profiles to shaking, a road embankment founded on a layered soil/rock model is considered. A scheme of the used numerical model and the FE mesh are given in Fig. 1(a) and Fig. 1(b) respectively. The geometry used in the FE model was inspired from the one proposed by López-Querol and Blázquez (2006).

The FE analysis is performed in four consecutive steps : i) Computation of the initial in-situ stress state due to gravity loads; ii) A sequential level-by-level construction and demolition of the preload embankment; iii) A sequential level-by-level construction of the road embankment and iv) seismic loading analysis in the time domain.

The soil profile is composed principally of $15 \mathrm{~m}$ of loose-to-medium sand (i.e. a relative density $\mathrm{Dr}<50 \%$ ) and to take into account the stress dependency of sand behaviour it is divided in three layers. The model parameters of each layer are adjusted so as to keep the 
same $D_{r}$ value. The shear modulus of the soil increases with the depth. The initial modulus $\left(G_{\max }\right)$ is computed by the following relationship :

$$
G_{\max }=290\left(\frac{\sigma_{m o}^{\prime}}{p_{\text {ref }}}\right)^{0.5} \quad[\mathrm{MPa}]
$$

where $\sigma_{m o}^{\prime}$ is the mean effective pressure and $p_{\text {ref }}$ is the pressure of reference $(1 \mathrm{MPa})$.

The low-strain frequency analysis provides a fundamental elastic period of the soil profile equal to 0.31s. It is obtained from the transfer function at free field condition, (i.e. ratio of the frequency response at the soil surface over the bedrock frequency response for a sample seismic signal at very low amplitude to ensure elastic soil behaviour). The elastoplastic multi-mechanism model briefly described before is used to represent the soil behaviour on the top $15 \mathrm{~m}$. For the engineering bedrock representing a half-space and placed at $15 \mathrm{~m}$ depth, an isotropic linear elastic behaviour with a $V_{s}$ equal to $550 \mathrm{~m} / \mathrm{s}$ is assumed. The ground water table level is placed at $1 \mathrm{~m}$ below the surface. The model is $80 \mathrm{~m}$ wide so as to ensure that the effect of the boundaries on the model response can be neglected and also to satisfy the free field condition at the lateral boundaries.

\section{Finite Element (FE) model}

A $2 \mathrm{D}$ coupled dynamic approach derived from the $\underline{u}-p_{w}$ version of the Biot's generalized consolidation theory (Zienkiewicz and Taylor 1991) was adopted for the soil. The so-called $\underline{u}-p_{w}$ formulation, consists of neglecting fluid acceleration terms and convective terms of this acceleration so that the unknown variables remain the displacement of the solid $\underline{u}$ and the pressure of the water $p_{w}$. The saturated soil was modelled using quadrilateral isoparametric elements with eight nodes for both solid displacements and fluid pressures. The size of elements is $0.5 \mathrm{~m} \times 0.5 \mathrm{~m}$. It was chosen in order to have 8 to 10 elements per wavelength which are sufficient to prevent numerical dispersion. An implicit Newmark numerical integration scheme with $\gamma=0.625$ and $\beta=0.375$ is used in the dynamic analysis (Kuhl and Crisfield 1999), this allows an optimal high-frequency dissipation with minimal low-frequency impact 
and adds a small numerical damping $(\xi \approx 0.2 \%)$. A plane-strain condition was assumed in the finite element model.

In order to investigate the effect of the preloading method on the response of the soil profile, a comparative dynamical response analysis at the end of shaking for the cases with and without mitigation method is done.

\section{Boundary conditions}

In the analysis, only vertically incident shear waves are introduced into the domain and as the response of an infinite semi-space is modelled, equivalent boundaries have been imposed on the nodes of lateral boundaries (i.e. the normal stress on these boundaries remains constant and the displacements of nodes at the same depth in two opposite lateral boundaries are the same in all directions). The model length is $80 \mathrm{~m}$. It ensures that the effect of the boundaries in the model can be neglected and it satisfies the free field condition at the lateral boundaries.

For the half-space bedrock's boundary condition, paraxial elements simulating "deformable unbounded elastic bedrock" have been used (Modaressi and Benzenati 1994). The incident waves, defined at the outcropping bedrock are introduced into the base of the model after deconvolution. Thus, the obtained movement at the bedrock is composed of the incident waves and the reflected signal.

\section{Preloading simulation}

In order to simulate the construction and demolition of the preload embankment (Fig. 1(b)), the calculations are performed in two steps. In the first step, since soil behaviour is a function of the effective stress state for nonlinear elastoplastic models, initial in-situ stress state due to gravity loads are computed. After this initialization, the displacements and deformations are eliminated and the initial effective stresses, pore-water pressures and model history variables are stored to be used as initial state of the second step computation. In the second one, a sequential level-by-level construction and demolition of the embankment is performed. 
The preload embankment is supposed to be in dry condition. It was simulated using quadrilateral isoparametric elements with eight nodes for solid displacements (Fig. 1(b)). The preload embankment height $\left(H_{e m b k}\right)$ is $7.5 \mathrm{~m}$ with a density equal to $1800 \mathrm{~kg} / \mathrm{m}^{3}$. The fill length is $38 \mathrm{~m}$ and the length at the crest is $4 \mathrm{~m}$. The preload embankment is constructed and demolished at a rate of $0.22 \mathrm{~m}$ /day and it stays in place during 23 days before the construction of the road embankment and the application of the seismic event. After this period and according to our computations all over pore pressures are dissipated.

\section{Road embankment model}

The road embankment was simulated using quadrilateral isoparametric elements with eight nodes for solid displacements (Fig. 1(b)). It is supposed to be in dry condition. It is $5 \mathrm{~m}$ high, $8 \mathrm{~m}$ wide at the crest and $20 \mathrm{~m}$ wide at the base. Its density $\left(\rho_{\text {road }}\right)$ is equal to $1800 \mathrm{~kg} / \mathrm{m}^{3}$. It consists of a base of dense sand (i.e. $D r>70 \%$ ). The soil behaviour is represented by an elastoplastic multi-mechanism model. The model parameters are summarized in Table 3. The road embankment is constructed at the same rate as that of the preload one.

A $0.40 \mathrm{~m}$ thick asphaltic pavement is placed on the top of the road embankment. It is assumed to have a linear elastic behaviour, with an elastic modulus, $\left(E_{a s p}\right)$, of 6000MPa, a Poisson's ratio, $\left(\nu_{a s p}\right)$, of 0.35 and a density, $\left(\rho_{a s p}\right)$, equal to $1800 \mathrm{~kg} / \mathrm{m}^{3}$. It was simulated using elastic beam-column elements.

\section{Input earthquake motion}

In order to define appropriate input motions to the non-linear dynamic analysis, a selection of recorded accelerograms are used. The adopted earthquake signals are proposed by Iervolino and Cornell (2005) and Sorrentino et al. (2008). Thus, 76 unscaled records were chosen from the Pacific Earthquake Engineering Research Center (PEER) database. The events range between 5.2 and 7.6 in magnitude and the recordings have site-to-source distances from 15 to $50 \mathrm{~km}$ and dense-to-firm soil conditions (i.e. $360 \mathrm{~m} / \mathrm{s}<V_{s} 30 \mathrm{~m}<800 \mathrm{~m} / \mathrm{s}$ ).

Concerning the response spectra of input earthquake motions, Fig. 2 shows the mean and the response spectra curves (structural damping $\xi=5 \%$ ) of the input motions. It can 
be noted that the mean response spectra is consistent with the response spectra of Type A soil of Eurocode8 scaled to the mean maximal outcropping acceleration value. The statistics on some input earthquake characteristics obtained for the strong ground motions are summarized in Table 2. These earthquake characteristics are maximal outcropping acceleration $(P H A)$, Arias intensity $\left(I_{A}\right)$ (Arias 1970), predominant period $\left(T_{p}\right)$, mean period $\left(T_{m}\right)$ (Rathje et al. 1998), peak ground velocity $(P G V)$, period of equivalent harmonic wave $\left(T_{V / A}=\alpha \cdot P G V / P H A\right)$, spectral intensity $(S I)$, root-mean-square intensity $\left(I_{r m s}\right)$ (Koutsourelakis et al. 2002), significant duration from 5\% to $95 \%$ Arias intensity $\left(D_{5-95}\right)$ and Specific Energy Density $(S E D)$.

\section{LABORATORY TESTS SIMULATIONS}

In order to show both a global view of the response of the ECP elastoplastic model and the coherence of the parameters set used to simulate the sand behaviour, several soil mechanics tests are modelled. All tests are simulated with the same set of parameters. The soil mechanics tests concern both drained cyclic strain-controlled and undrained stress controlled cyclic shear tests paths at different consolidation pressures

The model parameters of three layers are summarized in Table 3. They were determined with the methodology explained in Lopez-Caballero et al. (2007). In this methodology a unique and coherent set of the ECP model parameters is identified by modelling both monotonic and cyclic tests. As the model parameters are classified in two categories: directly and non-directly measurable parameters. In the first one, correlations or in-situ are used to define the parameter values. In the second one, the parameters are fixed by curve fitting. Fig. 3 shows the responses of the drained cyclic shear tests obtained by the model of the sand at $p_{o}^{\prime}=30,50,100$ and $150 \mathrm{kPa}$. The tests results are compared with the reference curves given by Seed et al. (1986). It is noted that the obtained $G / G_{\max }-\gamma$ curves match relatively good though for strains less than $0.01 \%$ the damping $D$ is underestimated while for large strains it is overestimated.

The obtained curves of cyclic stress ratio $\left(S R=\sigma_{v-c y c} /\left(2 \cdot p_{o}^{\prime}\right)\right.$, with $\sigma_{v-c y c}$ the cyclic 
vertical stress applied in the cyclic loading) in a triaxial path with isotropic consolidation as a function of the number of loading cycles to produce liquefaction $(N)$ at $p_{o}^{\prime}=30,50$ and $100 \mathrm{kPa}$ are given in Fig. 4. As qualitative comparison, the modelled test results are compared with the obtained curves given by Byrne et al. (2004) for Nevada sand at different densities (i.e. $D_{r}=40 \%$ and $60 \%$ ). It is noted that the obtained curves are placed between the experimental ones. It could be noted that the ECP elastoplastic model is able to simulate realistic liquefaction, $G-\gamma$ and $D-\gamma$ curves. In addition, according to these figures, the model's response for both loading paths is coherent for similar initial conditions.

So as to study the effect of overconsolidation on the cyclic strength some isotropic consolidation tests were simulated at $p_{o}^{\prime}=30$ and $50 \mathrm{kPa}$. Three levels of overconsolidation ratio $(O C R)$ were studied (i.e. 2,3 and 4$)$. The $O C R$ is defined as :

$$
O C R=\frac{\sigma_{v-c}^{\prime}}{p_{o}^{\prime}}
$$

where $\sigma_{v-c}^{\prime}$ is the maximum effective stress exerted during consolidation and $p_{o}^{\prime}$ is the effective stress just prior to the application of cyclic loading. It is important to remark that in this study only the behaviour of the case when $O C R=1$ is defined. Then, as in a real laboratory test, the completely loading path is simulated. It means that to reach a predefined $O C R$ value, an isotropic consolidation loading-unloading path is first simulated followed by a cyclic loading path. Fig. 5 displays the liquefaction curves obtained for the two initial stresses and two $O C R$ values. It is noted that for similar confining stress, the $S R$ value increase as $O C R$ increases, as shown in Adalier and Elgamal (2005), Wichtmann et al. (2005) and Stamatopoulos and Stamatopoulos (2007). These results allow to show the ability of the numerical code to simulate the effect of preloading in cyclic liquefaction strength.

\section{LIQUEFACTION ANALYSIS}

Before studying the seismic response of the road embankment without preloading, it is necessary to assess the modification on the behaviour of the soil foundation behaviour 
due to the presence of the road structure relative to the free field condition. As shown in Fig. 6(a) the road embankment load influences the soil behaviour down to $7.5 \mathrm{~m}$ depth (i.e. $\left.\Delta \sigma_{z z}>50 \mathrm{kPa}\right)$. Thus, it is expected that it produces a static bearing capacity degradation underneath the road embankment. According to the model parameters given in Table 3 and the Eq. 3, an initial value of the "distance to reach the critical state" $\left(r_{k}\right)$ (i.e. free field condition) equal to 0.5 is obtained. The contours of $\Delta r_{k}$ value (Fig. 6(b)) show that after the road embankment construction the $r_{k}$ value at shallow depths increases to near to 1.0 (i.e. $\left.\Delta r_{k} \approx 0.5\right)$.

In order to define the liquefaction reference case, the responses obtained by the model without preloading are analysed. Fig. 7 shows both a typical deformed configuration of the road embankment model and the distribution of induced horizontal displacements at the end of the earthquake loading. It could be noted that the liquefaction of soil foundation produces a lateral spreading of the foundation soil towards the free field. In addition, the liquefaction induces settlements at the crest due to the combined action of the migration of the underneath foundation soil and the deformation of the road embankment itself.

Fig. 8(a) displays the induced excess pore pressure $\left(\Delta p_{w}\right)$ distribution with depth in the soil profile below the embankment's foundation at the end of the signal (i.e. coseismic analyses) for all simulations. In this study, the end of shaking is defined as the time $t$ that corresponds to the $95 \%$ of Arias intensity $D_{95 I_{A}}$. It can be noted that, the flow liquefaction (i.e. $\Delta p_{w}=\sigma_{v o}^{\prime}$ ) or the full loss of effective stress in the soil does not occur for any input signal.

However, as expected, the development of excess pore pressure during the earthquake loading induces a shear strength degradation of the foundation soil which results in an accumulation of seismic settlements (Bouckovalas et al. 1991; Liu and Dobry 1997; Elgamal et al. 2002; Dashti et al. 2010a; Dashti et al. 2010b; Karamitros et al. 2013). Furthermore, co-seismic displacements are almost identical to permanent displacements. Fig. 8(b) shows the obtained co-seismic relative settlement at the base of the road embankment (i.e. point 
$F F_{p r}$ in Fig. 1(a)) induced by the pore water pressure build-up. The relative settlement of the road structure is computed as the difference between the settlement of the road embankment foundation and the free field settlement (i.e. point $F F_{N p}$ in Fig. 1(a)). It can be seen that, the co-seismic relative settlement value increases with an increase in the Arias intensity $\left(I_{A}\right)$ value, that is, an increase into the input seismic energy. This finding is similar with recent works which correlate with good accuracy sliding-block seismic displacement to Arias intensity (Chousianitis et al. 2014). It can be seen that most of the obtained relative settlements are less than $10 \mathrm{~cm}(\approx 60 \%$ of simulations $)$. According to the limit states suggested by Bird et al. (2006) for rigid body settlement, it corresponds to slight ( $\leq$ $10 \mathrm{~cm}$ ) damage level. According to SCDOT (2010), the maximum vertical settlement along the profile grade over the design life of the embankment is $20 \mathrm{~cm}$ (i.e. performance limit EV-01).

In Fig. 9(a), the relative horizontal displacement $\left(U_{H}\right)$ time histories for a point near to the slope of the road embankment (i.e. point $R d_{i n}$ in Fig. 1(a)) are illustrated for two typical earthquakes. As recalled before, the $U_{H}$ of the road structure is computed as the difference between the horizontal displacement of the road embankment (i.e. point $R d_{i n}$ ) and the free field horizontal displacement (i.e. point $F F_{N p}$ in Fig. 1(a)).

Finally, Fig. 9(b) displays the maximum $U_{H}$ induced by the pore water pressure build-up as a function of the $\left(I_{\text {Arias }}\right)$ value of input earthquake. It is observed that the maximum $U_{H}$ value is about four times less than the maximum settlement value and it increases with an increase in the Arias intensity value.

\section{ANALYSIS OF IMPROVEMENT METHOD}

In this section, the change in soil state due to the construction and demolition of the preload embankment is analyzed. The reference state corresponds to the soil foundation state after the construction of the road embankment. Normally, the application of preloading produces an overconsolidation on the soil $\left(O C R=\sigma_{v-c}^{\prime} / \sigma_{v o}^{\prime}\right)$ and a residual horizontal effective stress $\Delta \sigma_{y y}$ appears at the end of the demolition of the embankment. However, due 
to the adopted preloading configuration (Fig. 1) the induced $O C R$ was concentrated at the toe of the road slopes, namely, at the place of the preload embankment (Fig. 10(a)). At these places the embankment load influences the soil behaviour down to 3 to $4 \mathrm{~m}$ depth (i.e. $O C R>2$ ). In addition, comparing the induced horizontal effective stress for the case with and without preloading $\left(\Delta \sigma_{y y}\right)$ (Fig. 10(b)), it is interesting to note that at the toe of the road slopes, a residual $\Delta \sigma_{y y}$ appears.

Regarding the $r_{k}$ values, the contours of $\Delta r_{k}$ value (Fig. 11) show that the mitigation method produces an improvement on the static bearing capacity (i.e. $\Delta r_{k} \leq 0$ ) in the same places. This final configuration corresponds to the case named "Densification" in the series of centrifuge tests proposed by Adalier et al. (1998). The improvement on the static bearing capacity is confirmed by the fact that the settlement evolution obtained during the construction of the road embankment is less than 20 times when the preloading was used (Fig. 12).

Concerning the seismic response of the soil profile, the remediation method used increases the strength at the toe of the road which contains the loose sand stratum underneath the embankment centre and in consequence, it will decrease the relative settlement (Fig. 13(a)). As illustrated in this figure, the co-seismic structural relative settlement obtained after soil improvement is greatly reduced as a consequence of soil stiffening (e.g. more than two times). This results are in agreement with those obtained by Adalier et al. (1998) and Elgamal et al. (2002) among others. Fig. 13(b) displays the variation of $\Delta s e t t l=s e t t l_{m i t} / s e t t l_{o}$ (where mit and $o$ subscripts refer to values after and before mitigation respectively) as a function of the $I_{A}$ value. It could be remarked, that the reduction is most important for the lower values of $I_{A}$. In addition, the onset of the slight damage level apparition is shifted for the higher values of $I_{A}$, passing from $0.3 \mathrm{~m} / \mathrm{s}$ to $0.6 \mathrm{~m} / \mathrm{s}$.

Moreover, so as to quantify the extent of liquefaction into the profile below the embankment foundation, the Liquefaction Index $\left(Q_{H}\right)$ is computed. This parameter is defined as 
follows (Shinozuka and Ohtomo 1989):

$$
Q_{H}(t)=\frac{1}{H} \int_{0}^{H} \frac{\Delta p_{w}(t, z)}{\sigma_{v o}^{\prime}(z)} d z
$$

where $H$ is the selected depth (in this case, $H=10 \mathrm{~m}$ ), $\Delta p_{w}(t, z)$ is the pore water pressure build-up computed at time $t$ and depth $z$.

Fig. 13(c) provides the variation of $\Delta s e t t l=s e t t l_{m i t} / s t t l_{o}$ as a function of the variation of $Q_{H=10 \mathrm{~m}}$ value obtained bellow the road embankment for the case without preloading. It appears that in general the settlement reduction is most important for $Q_{H=10 \mathrm{~m}} \leq 0.4$ (i.e. red points in the figure). This $Q_{H=10 \mathrm{~m}}$ value means that the thickness of liquefied layer corresponds approximately to $4 \mathrm{~m}$, thus as aforementioned the effect of the preloading configuration influences the soil behaviour down to 3 to $4 \mathrm{~m}$ depth (Fig. 11). According to Yasuda (2007), the large induced settlement is produced principally by the horizontal movement of the ground under the structure. Thus, it seems that the mitigation efficiency is due to the lateral soil stiffening effect provided by the preloading which decreases the settlement reducing the horizontal movement of soil foundation.

Finally, regarding the effect of soil improvement on the induced relative horizontal displacement $\left(U_{H}\right)$ and in accordance with Fig. 14, it seems that a clear trend could not be distinguished. In some cases, the induced $U_{H}$ value after preloading exceeds the one obtained without preloading. A possible reason is that this horizontal displacement is related to a local shear failure of the embankment, which is not related to the actual state of the underlying soil. However, in order to reduce the horizontal displacement of the road embankment other complementary mitigation methods could be used, e.g. the placement of gravel berms on both sides of the road embankment.

\section{CONCLUSIONS}

A series of finite element parametric analyses were carried out so as to assess the performance of preloading embankment as a liquefaction countermeasure method in foundation of 
road embankments. A typical soil-road embankment model has been used to illustrate key results from parametric studies. Performance was assessed by means of overall road embankment behaviour, namely, settlements and horizontal displacements. The main conclusions drawn from this study are as follows.

- The countermeasure method and the used configuration produce a densification of the soil layers placed at the toe of the road slopes of the embankment which is a function of the preloading embankment height.

- The analyses showed that the use of preloading reduces the induced road embankment surface settlements. Because, the densified zones are able to limit lateral migration of foundation soil towards the free field.

- The results show that the preloading has a beneficial effect concerning the settlements in the cases where earthquakes produced a depth of liquefaction less than the depth of the overconsolidated soil. Thus, the countermeasure's effect should reach a certain depth to be effective.

- The threshold Arias intensity value needed to induce a slight damage level increases when the preloading method is used.

- After soil improvement, the settlement of soil foundation could be neglected for lower levels of excitation.

- The induced relative horizontal displacement is about four times less than the settlement and is not affected significantly by the preloading presumably because it may be related to shallow shear failure of the embankment, not passing through the layers of the underlying soil that liquefy.

- The numerical results for both the simulated laboratory tests and the road embankment allow to show that the numerical code used in this study is able to simulate the preloading method. Moreover, for the design purposes, it could be used as a tool for assessing the effectiveness of this liquefaction countermeasure method. 


\section{ACKNOWLEDGEMENTS}

This work was funded by the Seventh Framework Programme of the European Community, European Commission Research Executive Agency under Grant agreement FP7-SME2010-1-262161-PREMISERI. The research reported in this paper has been supported in part by the SEISM Paris Saclay Research Institute. 


\section{APPENDIX I. REFERENCES}

Adalier, K. and Aydingun, O. (2003). "Numerical analysis of seismically induced liquefaction in earth embankment foundations. Part II. Application of remedial measures." Canadian Geotechnical Journal, 40(4), 766-779.

Adalier, K. and Elgamal, A.-W. (2005). "Liquefaction of over-consolidated sand : a centrifuge investigation." Journal of Earthquake Engineering, 9(S1), 127-150.

Adalier, K., Elgamal, A.-W., and Martin, G. (1998). "Foundation liquefaction countermeasures for earth embankments." Journal of Geotechnical and Geoenvironmental Engineering, 124(6), 500-517.

Arias, A. (1970). "A mesure of earthquake intensity." Seismic Design for Nuclear Power Plants, R.J. Hansen (ed.), MIT Press, Cambridge, Massachusetts, 438-483.

Aubry, D., Hujeux, J.-C., Lassoudière, F., and Meimon, Y. (1982). "A double memory model with multiple mechanisms for cyclic soil behaviour." International symposium on numerical models in geomechanics, Balkema, 3-13.

Bird, J. F., Bommer, J. J., Crowley, H., and Pinho, R. (2006). "Modelling liquefactioninduced building damage in earthquake loss estimation." Soil Dynamics and Earthquake Engineering, 26(1), 15-30.

Bouckovalas, G., Stamatopoulos, C. A., and Whitman, R. V. (1991). "Analysis of seismic settlements and pore pressures in centrifuge tests." Journal of Geotechnical Engineering, 117(10), 1492-1508.

Bouferra, R., Benseddiq, N., and Shahrour, I. (2007). "Saturation and Preloading Effects on the Cyclic Behavior of Sand." International Journal of Geomechanics, 7(5), 396-401.

Bradley, B. A., Araki, K., Ishii, T., and Saitoh, K. (2013). "Effect of lattice-shaped ground improvement geometry on seismic response of liquefiable soil deposits via 3-D seismic effective stress analysis." Soil Dynamics and Earthquake Engineering, 48(1), 35-47.

Brennan, A. J. and Madabhushi, S. P. G. (2002). "Effectiveness of vertical drains in mitigation of liquefaction." Soil Dynamics and Earthquake Engineering, 22(9-12), 1059-1065. 
Byrne, P. M., Park, S.-S., Beaty, M., Sharp, M., Gonzalez, L., and Abdoun, T. (2004). "Numerical modeling of liquefaction and comparison with centrifuge tests." Canadian Geotechnical Journal, 41(2), 193-211.

Chousianitis, K., Gaudio, V. D., Kalogeras, I., and Ganas, A. (2014). "Predictive model of arias intensity and newmark displacement for regional scale evaluation of earthquakeinduced landslide hazard in greece." Soil Dynamics and Earthquake Engineering, 65(1), $11-29$.

Dashti, S., Bray, J. D., Pestana, J. M., Riemer, M., and Wilson, D. (2010a). "Centrifuge testing to evaluate and mitigate liquefaction-induced building settlement mechanisms." Journal of Geotechnical and Geoenvironmental Engineering, 136(7), 918-930.

Dashti, S., Bray, J. D., Pestana, J. M., Riemer, M., and Wilson, D. (2010b). "Mechanisms of seismically induced settlement of buildings with shallow foundations on liquefiable soil." Journal of Geotechnical and Geoenvironmental Engineering, 136(1), 151-164.

Elgamal, A.-W., Lu, J., and Yang, Z. (2005). "Liquefaction-induced settlement of shallow foundations ans remediation : 3D Numerical simulation." Journal of Earthquake Engineering, 9(1), 17-45.

Elgamal, A.-W., Parra, E., Yang, Z., and Adalier, K. (2002). "Numerical analysis of embankment foundation liquefaction countermeasures." Journal of Earthquake Engineering, $6(4), 447-471$.

Hujeux, J.-C. (1985). "Une loi de comportement pour le chargement cyclique des sols." Génie Parasismique, V. Davidovici, Presses ENPC, France, 278-302.

Iervolino, I. and Cornell, C. A. (2005). "Record selection for nonlinear seismic analysis of structures." Earthquake Spectra, 21(3), 685-713.

Ishihara, K. and Okada, S. (1982). "Effects of large preshearing on cyclic behavior of sand." Soils and Foundations, 22(3), 109-125.

Kaneko, M., Sasaki, Y., Nishikawa, J., Nagase, M., and Mamiya, K. (1995). "River dike failure in japan by earthquakes in 1993." Third International Conference on recent Advances 
in Geotechnical Earthquake Engineering and Soil Dynamics, Vol. 1, St. Louis, Missouri. Eds. Prakash, 495-498.

Karamitros, D., Bouckovalas, G., and Chaloulos, Y. (2013). "Insight into the seismic liquefaction performance of shallow foundations." Journal of Geotechnical and Geoenvironmental Engineering, 139(4), 599-607.

Koutsourelakis, S., Prévost, J. H., and Deodatis, G. (2002). "Risk assessment of an interacting structure-soil system due to liquefaction." Earthquake Engineering and Structural Dynamics, 31(4), 851-879.

Kuhl, D. and Crisfield, M. A. (1999). "Energy-conserving and decaying algorithms in nonlinear structural dynamics." International Journal for Numerical Methods in Engineering, 45(11), 569-599.

Liu, C. and Xu, J. (2013). "Experimental study on the effects of initial conditions on liquefaction of saturated and unsaturated sand." International Journal of Geomechanics, 10.1061/(ASCE)GM.1943-5622.0000350, 04014100.

Liu, L. and Dobry, R. (1997). "Seismic response of shallow foundation on liquefiable sand." Journal of Geotechnical and Geoenvironmental Engineering, 123(6), 557-567.

Lopez-Caballero, F. and Modaressi-Farahmand-Razavi, A. (2008). "Numerical simulation of liquefaction effects on seismic SSI." Soil Dynamics and Earthquake Engineering, 28(2), $85-98$.

Lopez-Caballero, F. and Modaressi-Farahmand-Razavi, A. (2013). "Numerical simulation of mitigation of liquefaction seismic risk by preloading and its effects on the performance of structures." Soil Dynamics and Earthquake Engineering, 49(1), 27-38.

Lopez-Caballero, F., Modaressi-Farahmand-Razavi, A., and Modaressi, H. (2007). "Nonlinear numerical method for earthquake site response analysis I- elastoplastic cyclic model \& parameter identification strategy." Bulletin of Earthquake Engineering, 5(3), 303-323.

López-Querol, S. and Blázquez, R. (2006). "Identification of failure mechanisms of road embankments due to liquefaction : optimal corrective measures at seismic sites." Canadian 
Geotechnical Journal, 43(9), 889-902.

Lu, J., Elgamal, A., Yan, L., Law, K. H., and Conte, J. P. (2011). "Large-Scale Numerical Modeling in Geotechnical Earthquake Engineering." International Journal of Geomechanics, 11(6), 490-503.

Marcuson, W. F., Hadala, P. F., and Ledbetter, R. H. (1996). "Seismic rehabilitation of earth dams." Journal of the Geotechnical Engineering Division - ASCE, 122(1), 7-20.

Matsuo, O. (1996). "Damage to river dikes." Soils and Foundations, 36(1), 235-240.

Mitrani, H. and Madabhushi, S. P. G. (2012). "Rigid containment walls for liquefaction remediation." Journal of Earthquake and Tsunami, 6(3), 1-23.

Modaressi, H. and Benzenati, I. (1994). "Paraxial approximation for poroelastic media." Soil Dynamics and Earthquake Engineering, 13(2), 117-129.

Nishimura, S.-I. and Shimizu, H. (2008). "Reliability-based design of ground improvement for liquefaction mitigation." Structural Safety, 30(3), 200-216.

Okamura, M., Tamamura, S., and Yamamoto, R. (2013). "Seismic stability of embankments subjected to pre-deformation due to foundation consolidation." Soils and Foundations, $53(1), 11-22$.

Petridis, P., Stamatopoulos, C., and Stamatopoulos, A. (2000). "Soil improvement by preloading of two erratic sites." GeoEng2000, International Conference on Geotechnical and Geological Engineering, Melbourne, Australia, 7p.

Porcino, D., Marciano, V., and Ghionna, V. N. (2009). "Influence of cyclic pre-shearing on undrained behavior of carbonate sand in simple shear tests." Geomechanics and Geoengineering: An International Journal, 4(2), 151-161.

Raptakis, D. G. (2013). "Pre-loading effect on site response: Site amplification and soil properties mismatch." Soil Dynamics and Earthquake Engineering, 53(1), 1 - 10.

Rathje, E. M., Abrahamson, N. A., and Bray, J. D. (1998). "Simplified frequency content estimates of earthquake ground motions." Journal of Geotechnical and Geoenvironmental Engineering, 124(2), 150-159. 
Sasaki, Y., Tamura, K., Yamamoto, M., and Ohbayashi, J. (1995). "Soil improvement work for river embankment damage by 1993 kushiro-oki earthquake." Proceedings of the First International Conference on Earthquake Geotechnical Engineering, Tokyo, Japan, Vol. 1, Balkema, 43-48.

SCDOT (2010). "Geotechnical design manual." Report no., South Carolina Department of Transportation, v1.1, Columbia, SC.

Seed, H. B., Wong, R. T., Idriss, I. M., and Tokimatsu, K. (1986). "Moduli and damping factors for dynamic analyses of cohesionless soils." Journal of Geotechnical Engineering ASCE, 112(11), 1016-1032.

Shahir, H. and Pak, A. (2010). "Estimating liquefaction-induced settlement of shallow foundations by numerical approach." Computers and Geotechnics, 37(3), 267-279.

Shinozuka, M. and Ohtomo, K. (1989). "Spatial severity of liquefaction." Proceedings of the second US-Japan workshop in liquefaction, large ground deformation and their effects on lifelines.

Sorrentino, L., Kunnath, S., Monti, G., and Scalora, G. (2008). "Seismically induced onesided rocking response of unreinforced masonry façades." Engineering Structures, 30(8), $2140-2153$.

Stamatopoulos, A. C. and Kotzias, P. C. (1985). Soil improvement by preloading. John Wiley and Sons Inc.

Stamatopoulos, C., Petridis, P., Bassanou, M., Allkja, S., Loukatos, N., and Small, A. (2013). "Improvement of dynamic soil properties induced by preloading verified by a field test." Engineering Geology, 163(1), $101-112$.

Stamatopoulos, C., Petridis, P., Bassanou, M., and Stamatopoulos, A. (2005). "Increase in horizontal stress induced by preloading." Ground Improvement, 9(2), 47-51.

Stamatopoulos, C. A. and Stamatopoulos, A. (2007). "Effect of preloading on the cyclic strength of reconstituted sand." Ground Improvement, 11(3), 145-155.

Tika, T. E. and Pitilakis, K. D. (1999). "Liquefaction induced failure of a bridge embank- 
ment." Proceedings of the Second International Conference on Earthquake Geotechnical Engineering, Lisbon, Balkema, 631-636.

Unjoh, S., Kaneko, M., Kataoka, S., Nagaya, K., and Matsuoka, K. (2012). "Effect of earthquake ground motions on soil liquefaction." Soils and Foundations, 52(5), 830-841.

Wichtmann, T., Niemunis, A., Triantafyllidis, T., and Poblete, M. (2005). "Correlation of cyclic preloading with the liquefaction resistance." Soil Dynamics and Earthquake Engineering, 25(12), 923-932.

Xu, L.-Y., Cai, F., Wang, G.-X., Ugai, K., Wakai, A., Yang, Q.-Q., and Onoue, A. (2013). "Numerical assessment of liquefaction mitigation effects on residential houses: Case histories of the 2007 Niigata Chuetsu-offshore earthquake." Soil Dynamics and Earthquake Engineering, 53(1), 196-209.

Yasuda, S. (2007). "Remediation methods againts liquefaction which can be applied to existing structures." Earthquake Geotechnical Engineering, K.D. Pitilakis Ed., Springer, The Netherlands, 385-406.

Youd, T. L. (1993). "Liquefaction-induced damage to bridges." Transportation Research Record 1411, Transportation Research Board, National Research Council, Washington, D.C.

Zienkiewicz, O. C. and Taylor, R. L. (1991). The Finite element method, solid and fluid mechanics, dynamics and non-linearity, Vol. 2. McGraw-Hill Book Company, London, 4th edition. 


\section{List of Tables}

1 Classification of the ECP model parameters . . . . . . . . . . . . 23

2 Statistics characteristics for the selected earthquakes . . . . . . . . . 24

$3 \quad$ ECP model's parameters for all soil profile layers. . . . . . . . . . . . . 25 
TABLE 1. Classification of the ECP model parameters

Behaviour domains

\begin{tabular}{l|cc}
\hline Elasticity & $K_{r e f}, G_{r e f}, n_{e}, p_{\text {ref }}$ & \\
Critical State and Plasticity & $\phi_{p p}^{\prime}, \beta, p_{c o}, d$ & $b$ \\
Flow Rule and & $\psi$ & $a_{1}, a_{2}, \alpha_{\psi}$, \\
Isotropic hardening & & $m, c$ \\
Threshold domains & & $r^{\text {ela }}, r^{\text {hys }}$, \\
& & $r^{\text {mob }}, r_{\text {iso }}^{\text {ela }}$ \\
\hline
\end{tabular}


TABLE 2. Statistics characteristics for the selected earthquakes

\begin{tabular}{lccccc}
\hline Parameter & Range & Mean & $C V[\%]$ & Median & $\sigma_{\ln }$ \\
\hline$P H A[\mathrm{~g}]$ & $0.04-0.37$ & 0.14 & 53 & 0.11 & 0.49 \\
$T_{m}[\mathrm{~s}]$ & $0.37-1.27$ & 0.67 & 29 & 0.62 & 0.28 \\
$T_{p}[\mathrm{~s}]$ & $0.10-1.07$ & 0.41 & 53 & 0.40 & 0.57 \\
$T_{V / A}[\mathrm{~s}]$ & $0.26-1.54$ & 0.56 & 39 & 0.53 & 0.34 \\
$I_{A}[\mathrm{~m} / \mathrm{s}]$ & $0.03-3.13$ & 0.40 & 133 & 0.20 & 0.96 \\
$D_{5-95}[\mathrm{~s}]$ & $7.16-51.47$ & 18.11 & 42 & 17.22 & 0.36 \\
$I_{r m s}\left[\mathrm{~m} / \mathrm{s}^{2}\right]$ & $0.10-0.48$ & 0.22 & 44 & 0.19 & 0.41 \\
$P G V[\mathrm{~cm} / \mathrm{s}]$ & $3.19-63.70$ & 15.74 & 74 & 0.12 & 0.62 \\
$S I[\mathrm{~m}]$ & $0.12-2.51$ & 0.63 & 72 & 0.44 & 0.60 \\
$S E D\left[\mathrm{~cm}^{2} / \mathrm{s}\right]$ & $16.64-6150$ & 781 & 168 & 245 & 1.28 \\
\hline
\end{tabular}


TABLE 3. ECP model's parameters for all soil profile layers.

\begin{tabular}{ccccc} 
Parameter & $0-5 \mathrm{~m}$ & $5-10 \mathrm{~m}$ & $10-15 \mathrm{~m}$ & Road emb. \\
\hline$k_{s}[\mathrm{~m} / \mathrm{s}]$ & $1 \cdot 10^{-4}$ & $1 \cdot 10^{-4}$ & $1 \cdot 10^{-4}$ & - \\
Elasticity & \multicolumn{5}{c}{${ }^{-4}$} \\
$K_{\text {ref }}[\mathrm{MPa}]$ & 628 & 628 & 628 & 708 \\
$G_{\text {ref }}[\mathrm{MPa}]$ & 290 & 290 & 290 & 328 \\
$n_{e}$ & 0.5 & 0.5 & 0.5 & 0.4 \\
Critical State and Plasticity \\
$\left.\phi_{p p}^{\prime}{ }^{\circ}\right]$ \\
$\beta$ & 30 & 30 & 30 & 33 \\
$\beta$ & 33 & 33 & 33 & 17 \\
$d$ & 2.0 & 2.0 & 2.0 & 2.5 \\
$b$ & 0.2 & 0.2 & 0.2 & 0.2 \\
$p_{c o}^{\prime}[\mathrm{kPa}]$ & 18.9 & 39.8 & 60.8 & $7.2 \cdot 10^{3}$ \\
Flow Rule and Isotropic Hardening & & \\
$\left.\psi{ }^{\circ}\right]$ & 30 & 30 & 30 & 33 \\
$a_{1}$ & $1 \cdot 10^{-4}$ & $1 \cdot 10^{-4}$ & $1 \cdot 10^{-4}$ & $2 \cdot 10^{-4}$ \\
$a_{2}$ & $2 \cdot 10^{-3}$ & $2 \cdot 10^{-3}$ & $2 \cdot 10^{-3}$ & $1.8 \cdot 10^{-2}$ \\
$c$ & $2 \cdot 10^{-3}$ & $2 \cdot 10^{-3}$ & $2 \cdot 10^{-3}$ & $1 \cdot 10^{-4}$ \\
$m$ & 1.5 & 1.5 & 1.5 & 1.0 \\
Threshold Domains & \multicolumn{3}{c}{} \\
$r^{\text {ela }}$ & $3 \cdot 10^{-2}$ & $2 \cdot 10^{-2}$ & $1 \cdot 10^{-2}$ & $1 \cdot 10^{-2}$ \\
$r^{\text {hys }}$ & $4 \cdot 10^{-2}$ & $4 \cdot 10^{-2}$ & $4 \cdot 10^{-2}$ & $5 \cdot 10^{-2}$ \\
$r^{\text {mob }}$ & $8 \cdot 10^{-1}$ & $8 \cdot 10^{-1}$ & $8 \cdot 10^{-1}$ & $9 \cdot 10^{-1}$ \\
\hline
\end{tabular}

For all cases $p_{\text {ref }}=1.0 \mathrm{MPa}$ and $\alpha_{\psi}=1$. 


\section{List of Figures}

1 a) Schema of the numerical model and b) Finite element mesh of the road embankment and the remediation method. . . . . . . . . . . . . . 27

2 Response spectra of input earthquake motions (5\% damped). . . . . . . . 28

3 Simulated a) $G / G_{\max }-\gamma$ and b) $D-\gamma$ curves for the sand model. . . . . 29

4 Simulated liquefaction curves for the sand model. . . . . . . . . . . . . . . 30

5 Simulated liquefaction curves for the sand model, effect of overconsolidation ratio $(O C R)$ a) $p_{o}^{\prime}=30 \mathrm{kPa}$ and b) $p_{o}^{\prime}=50 \mathrm{kPa}$. . . . . . . . . 31

6 Distribution of the a) induced $\Delta \sigma_{z z}$ and b) obtained $\Delta r_{k}$ parameter (Eq. 3) in the soil foundation after road embankment construction $\left(H_{e m b k}=5 m\right)$. Case before preloading. . . . . . . . . . . . . . . . . 32

$7 \quad$ Typical distribution of induced horizontal displacements at the end of shaking (units in metres). Case before preloading. . . . . . . . . . . . . . . . 33

8 a) Obtained excess pore pressure under the road embankment centreline and b) Scatter plot of obtained co-seismic relative settlement values as a function of $I_{A}$. Case before preloading. . . . . . . . . . . . . . . . . . . 34

9 a) Relative horizontal displacement time histories of the point $R d_{\text {in }}$ for two typical earthquakes and b) Scatter plot of obtained co-seismic relative horizontal displacement values as a function of $I_{\text {Arias }}$. Case before preloading. . .

10 a) Overconsolidation ratio $(O C R)$ in the soil induced by the preload and b) Change in horizontal stress $\Delta \sigma_{y y}$ in the soil induced by the preload after road embankment construction. . . . . . . . . . . . . . . . . 36

11 Change in the $r_{k}$ parameter (Eq. 3) in the soil foundation induced by the preloading $\left(H_{e m b k}=5 \mathrm{~m}\right) . \ldots \ldots \ldots \ldots$

12 Effect of preload on the settlement obtained during the construction of the road embankment. 
13 Effect of preload embankment on the obtained a) co-seismic relative settlement values; b) Scatter plot of obtained $\Delta$ settl values as a function of $I_{A}$ and c) Scatter plot of obtained $\Delta s e t t l$ values as a function of Liquefaction Index $\left(Q_{H}\right) .39$

14 Effect of preload embankment on the obtained co-seismic relative horizontal displacement values. . . . . . . . . . . . . . . . . . . . . . . 40 

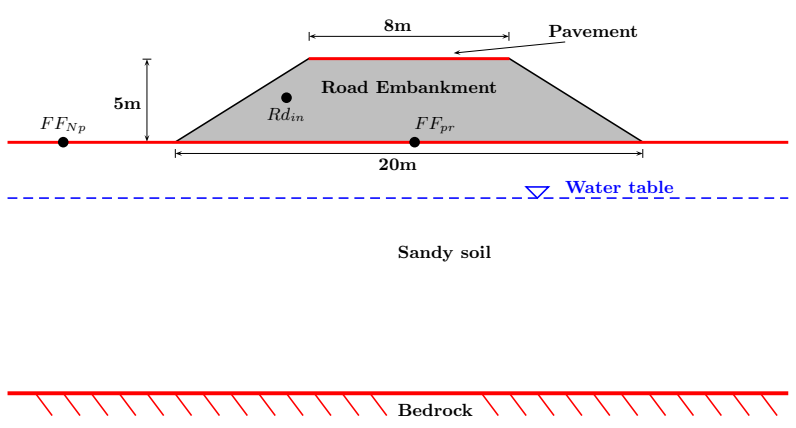

(a)

(a)

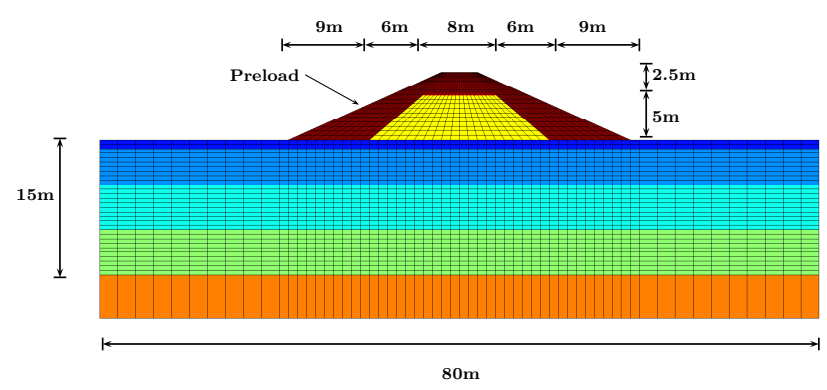

(b)

(b)

FIG. 1. a) Schema of the numerical model and b) Finite element mesh of the road embankment and the remediation method. 


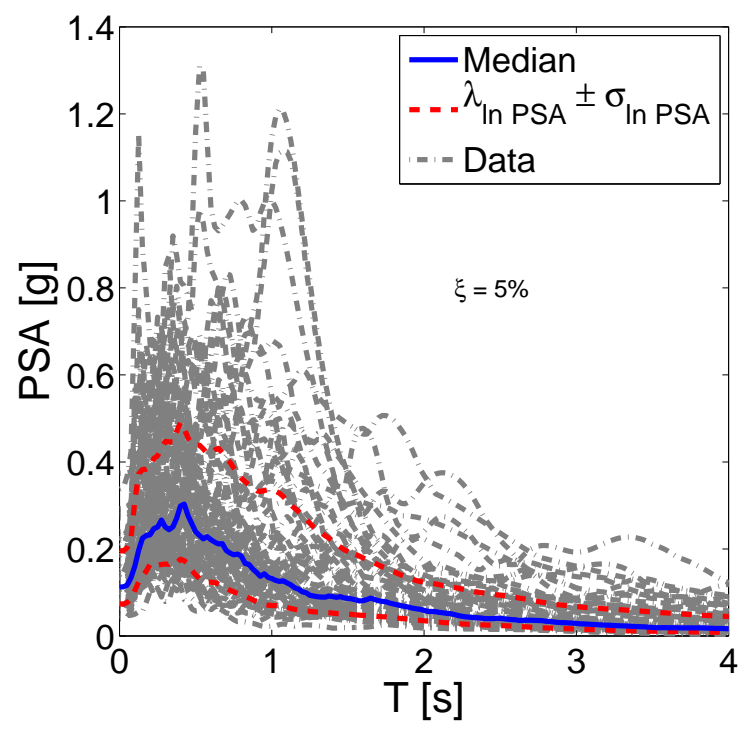

FIG. 2. Response spectra of input earthquake motions (5\% damped). 


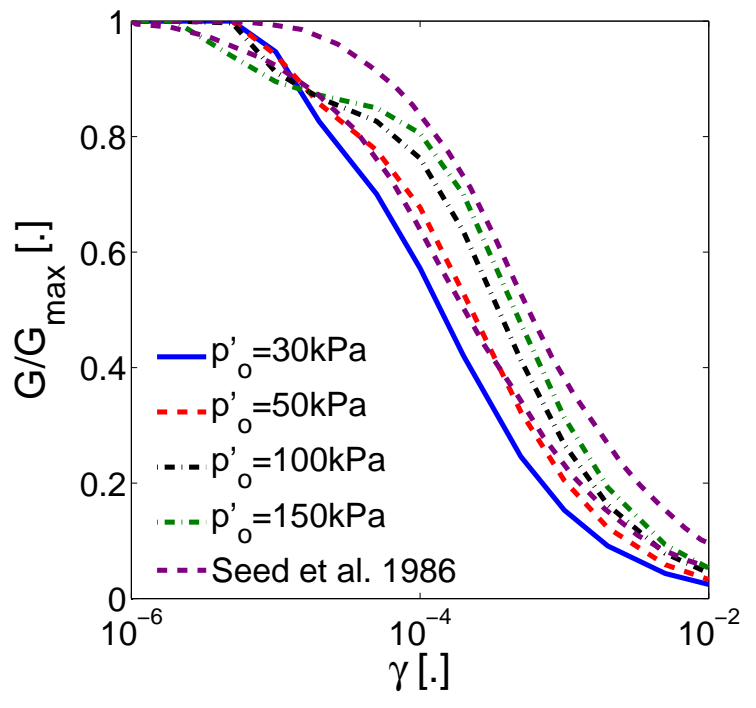

(a)

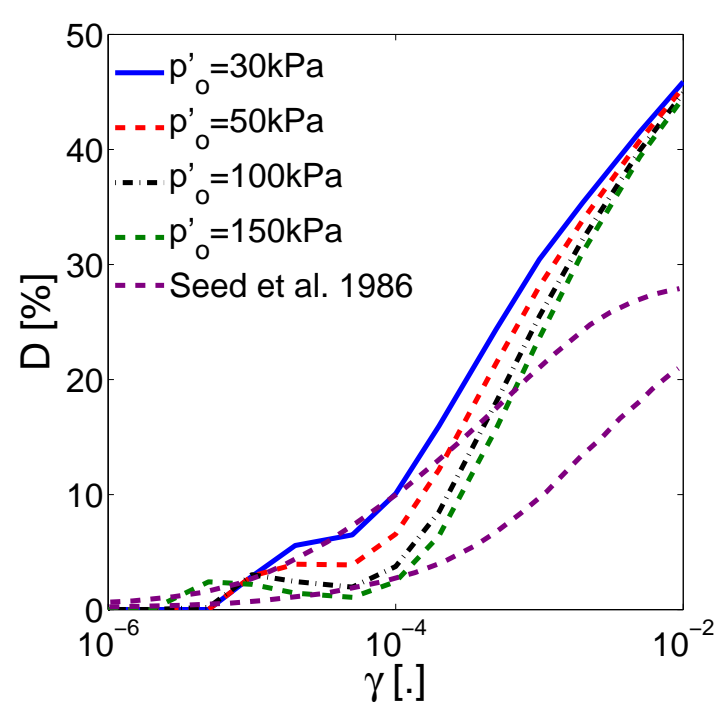

(b)

(a)

(b)

FIG. 3. Simulated a) $G / G_{\max }-\gamma$ and b) $D-\gamma$ curves for the sand model. 


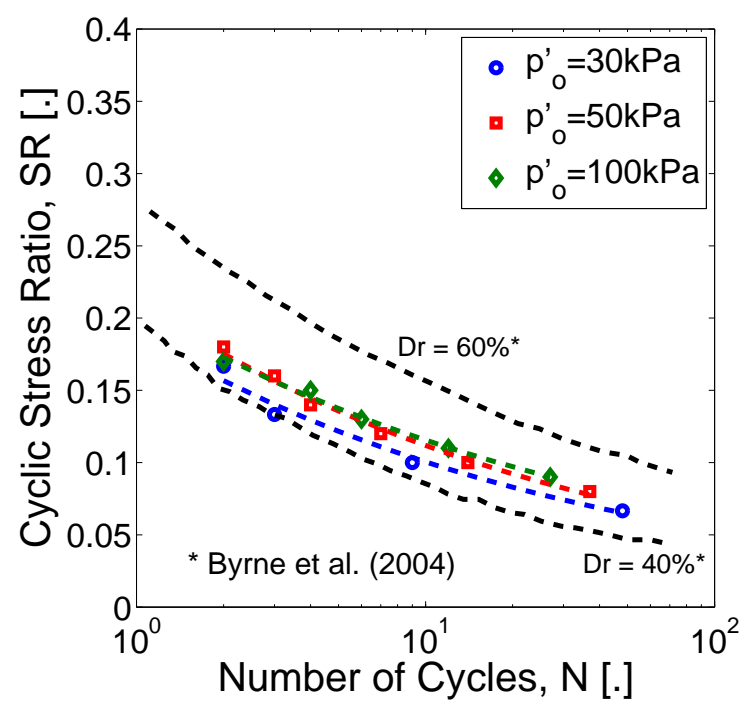

FIG. 4. Simulated liquefaction curves for the sand model. 


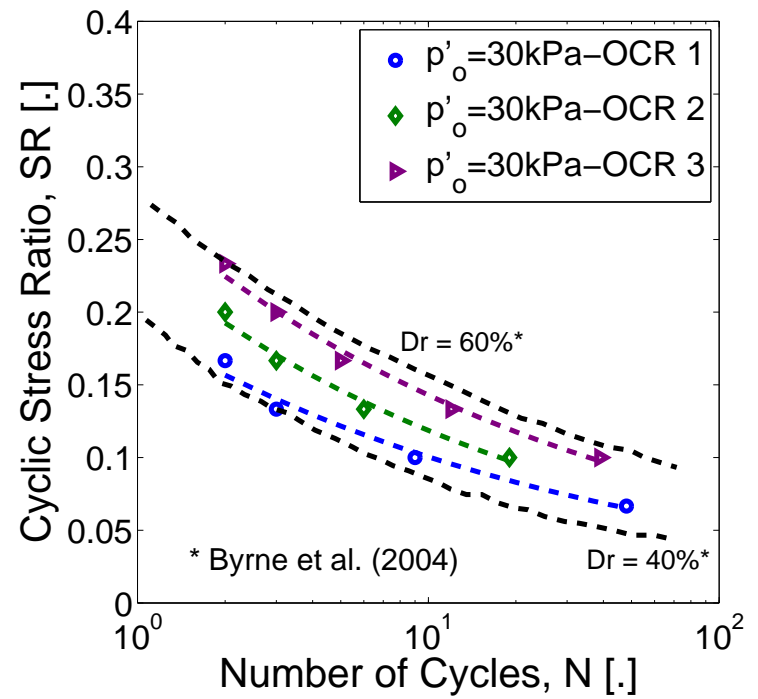

(a)

(a)

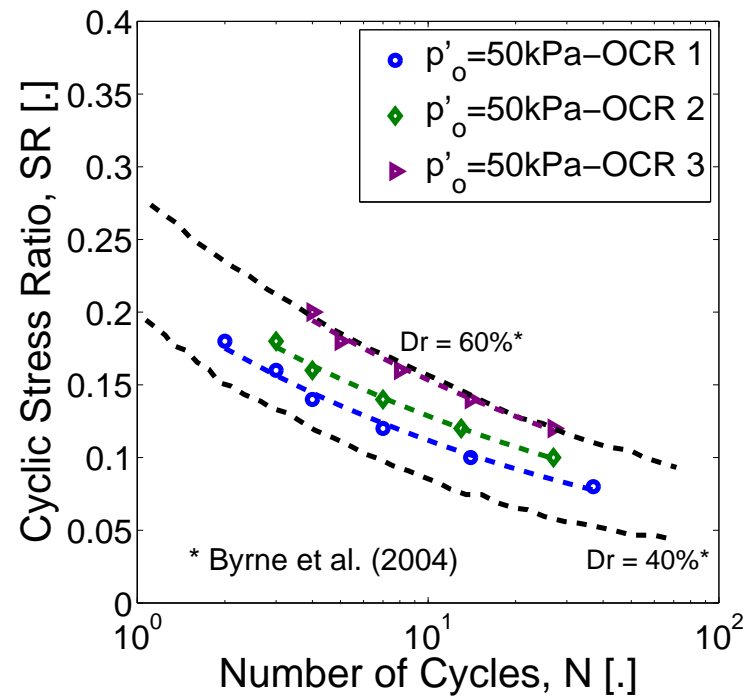

(b)

(b)

FIG. 5. Simulated liquefaction curves for the sand model, effect of overconsolidation ratio $(O C R)$ a) $p_{o}^{\prime}=30 \mathbf{k P a}$ and $\left.\mathbf{b}\right) p_{o}^{\prime}=50 \mathbf{k P a}$. 


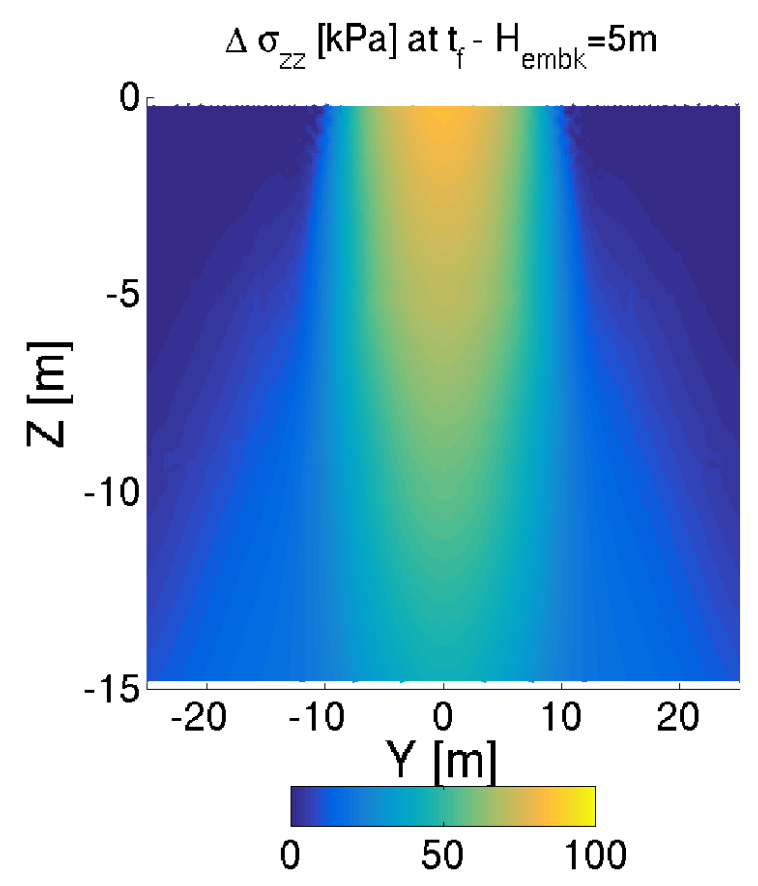

(a)

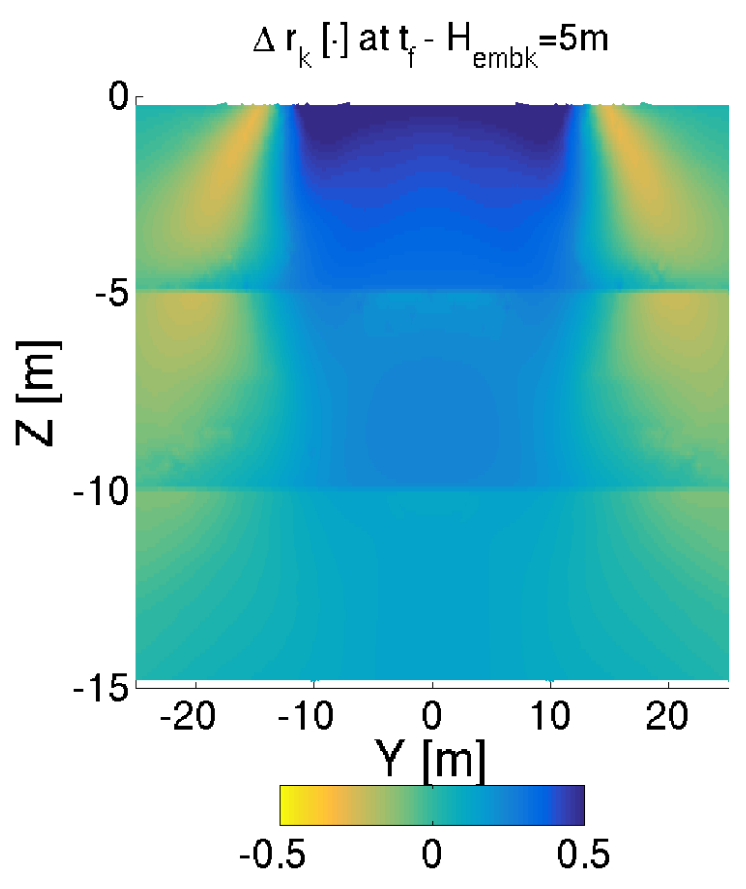

(b)

(a)

(b)

FIG. 6. Distribution of the a) induced $\Delta \sigma_{z z}$ and b) obtained $\Delta r_{k}$ parameter (Eq. 3) in the soil foundation after road embankment construction $\left(H_{e m b k}=5 \mathrm{~m}\right)$. Case before preloading. 

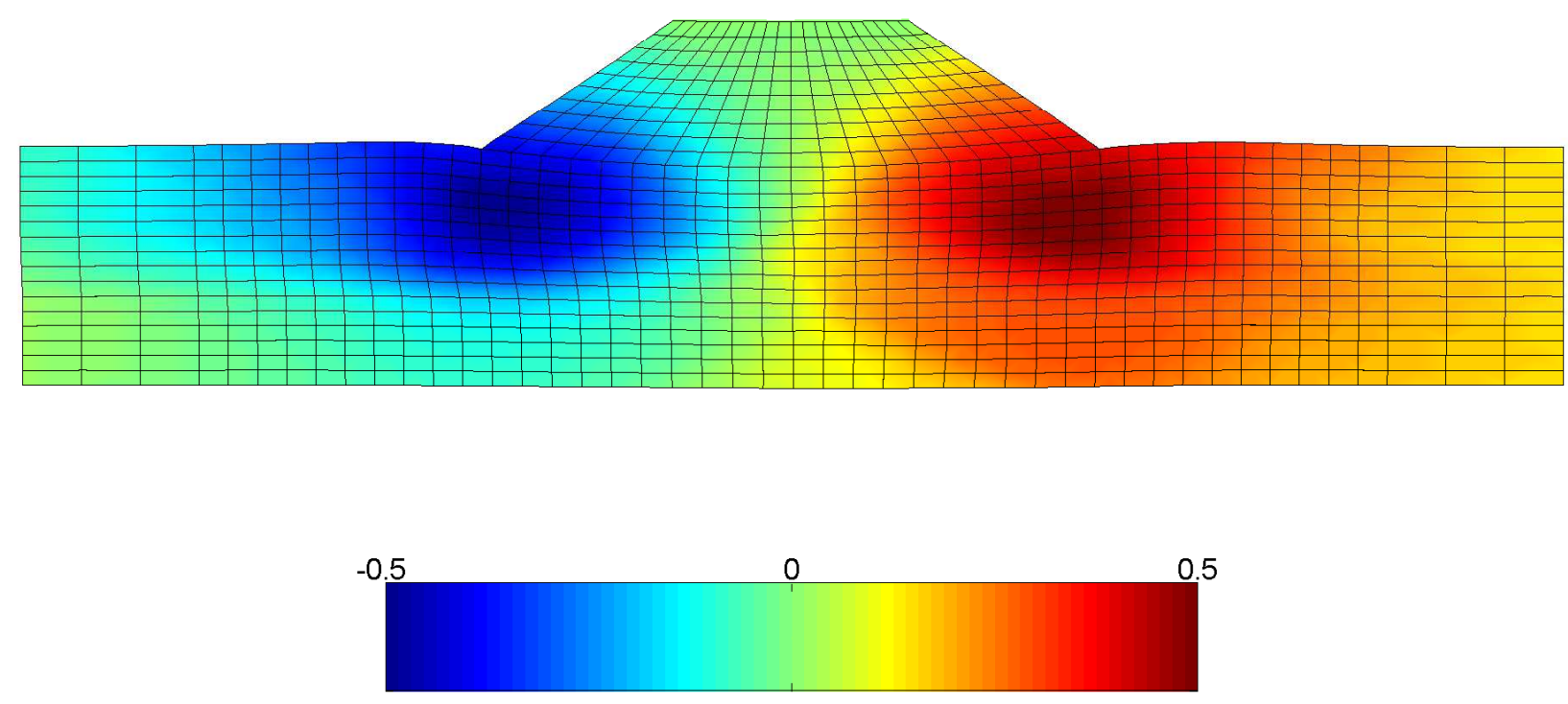

FIG. 7. Typical distribution of induced horizontal displacements at the end of shaking (units in metres). Case before preloading. 


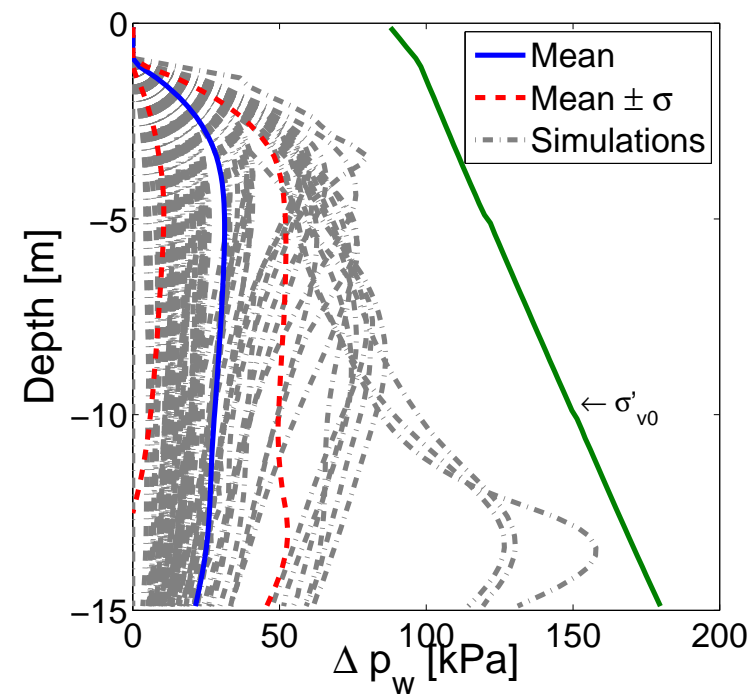

(a)

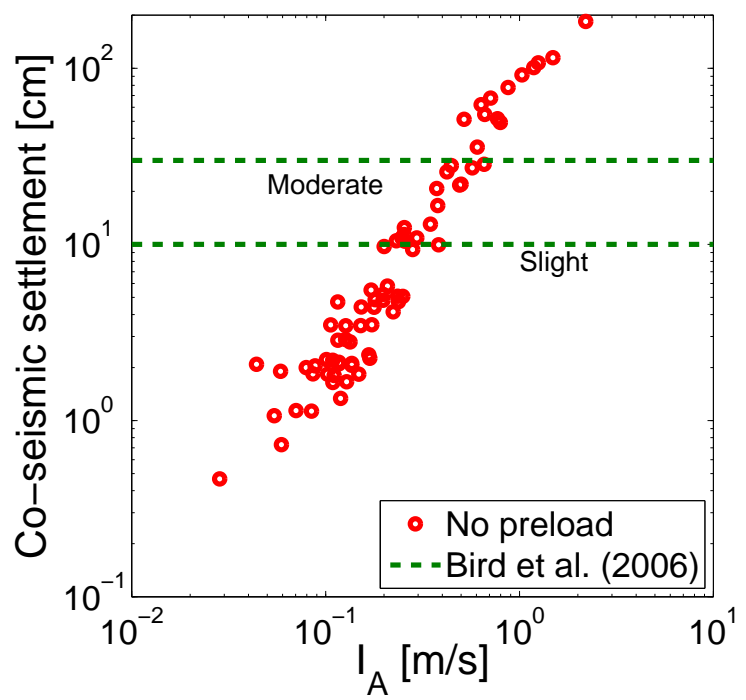

(b)

(a)

(b)

FIG. 8. a) Obtained excess pore pressure under the road embankment centreline and b) Scatter plot of obtained co-seismic relative settlement values as a function of $I_{A}$. Case before preloading. 


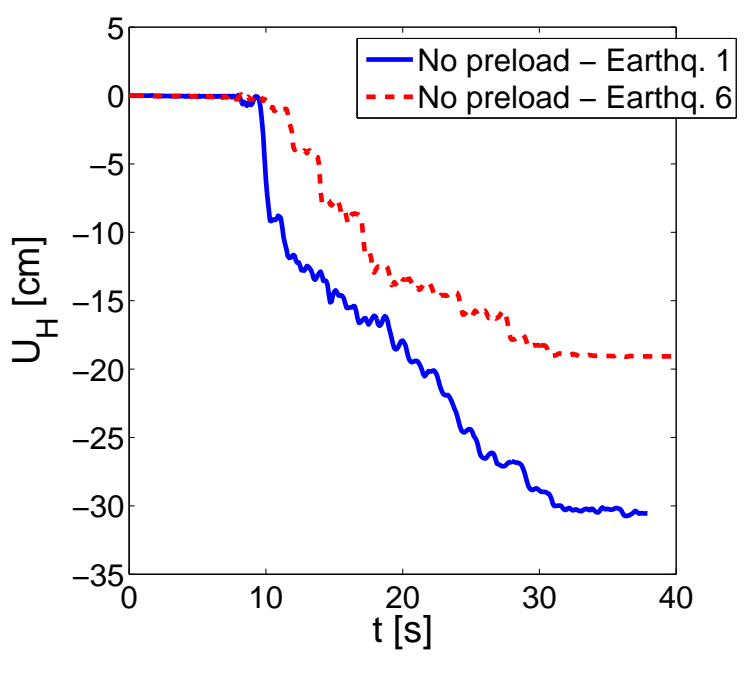

(a)

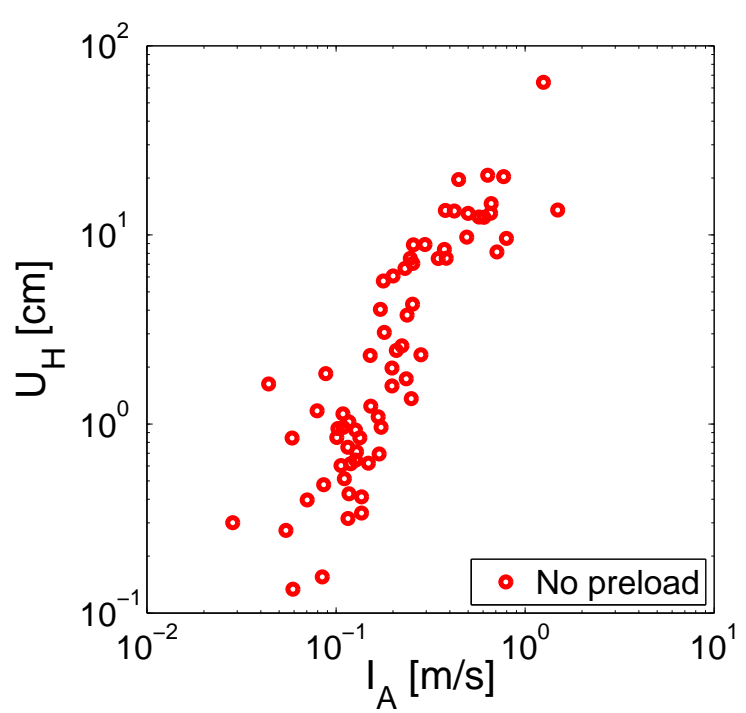

(b)

(a)

(b)

FIG. 9. a) Relative horizontal displacement time histories of the point $R d_{i n}$ for two typical earthquakes and b) Scatter plot of obtained co-seismic relative horizontal displacement values as a function of $I_{\text {Arias }}$. Case before preloading. 


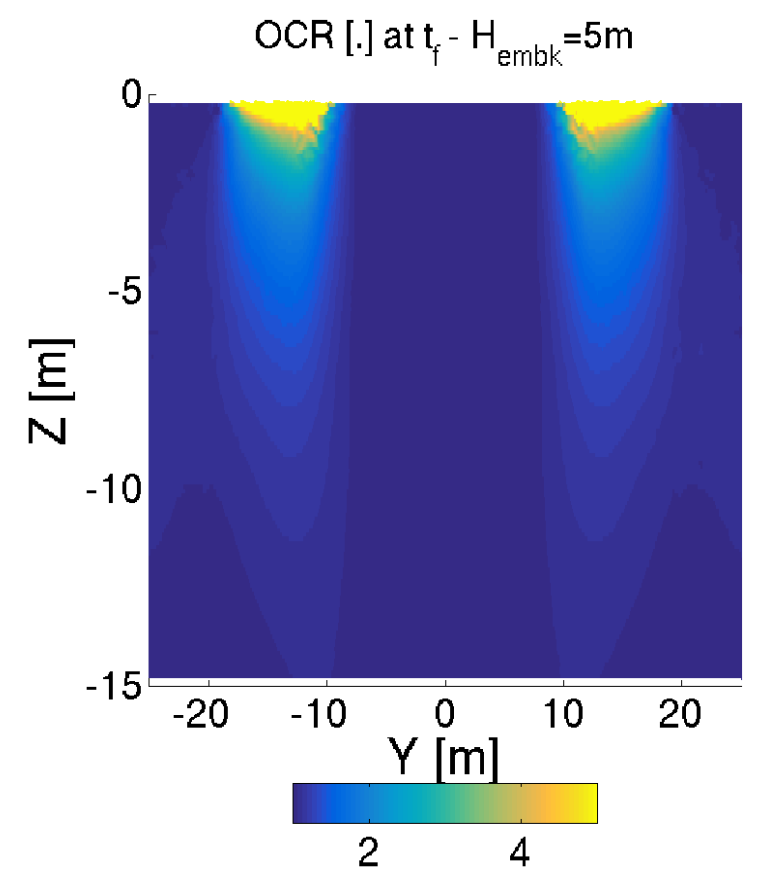

(a)

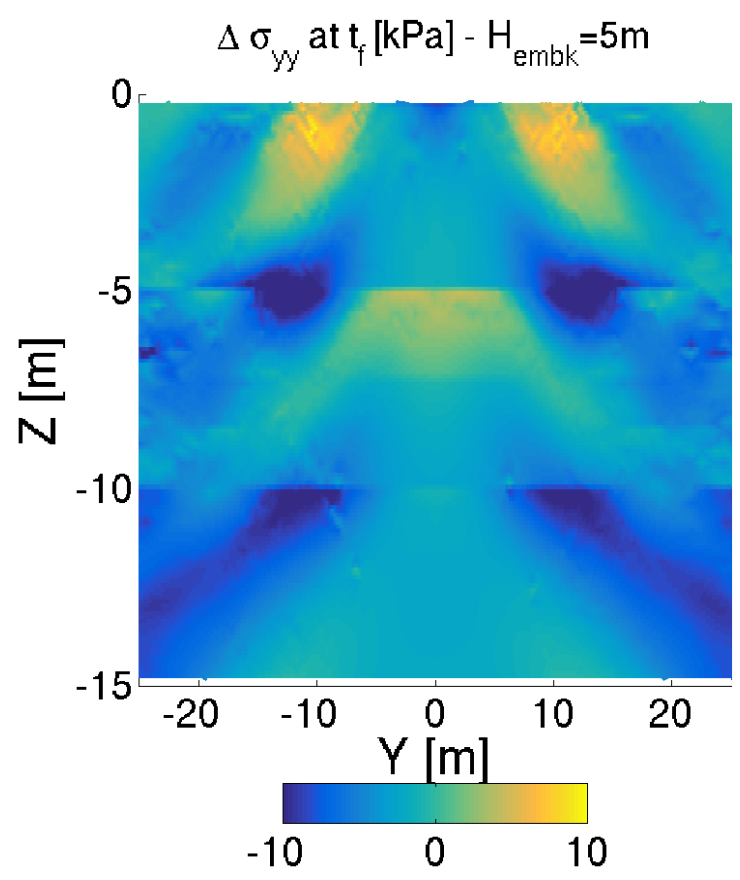

(b)

(a)

(b)

FIG. 10. a) Overconsolidation ratio $(O C R)$ in the soil induced by the preload and b) Change in horizontal stress $\Delta \sigma_{y y}$ in the soil induced by the preload after road embankment construction. 


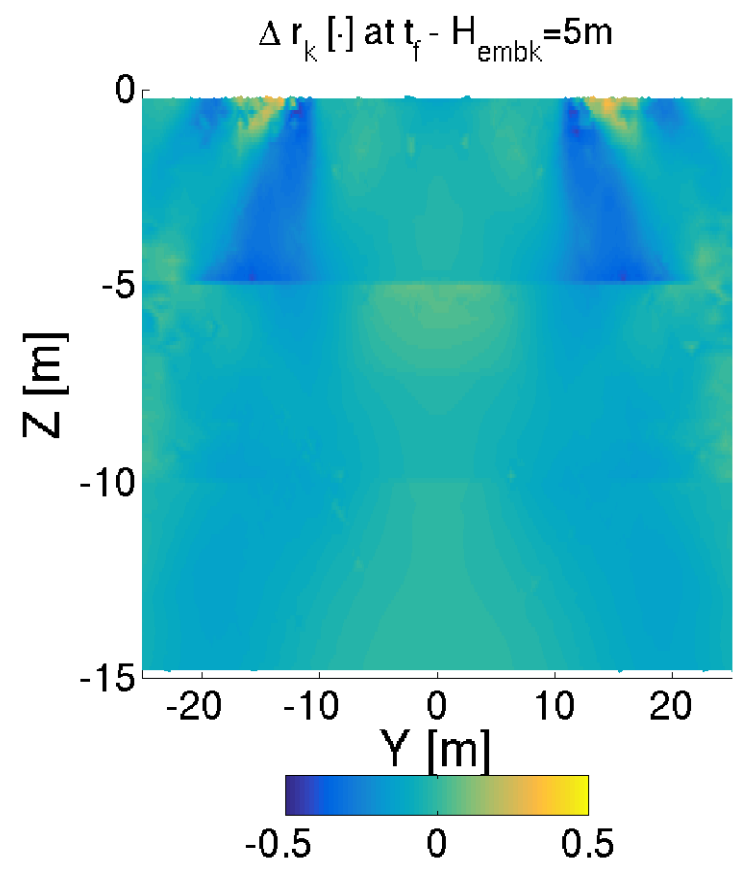

FIG. 11. Change in the $r_{k}$ parameter (Eq. 3) in the soil foundation induced by the preloading $\left(H_{e m b k}=5 \mathbf{m}\right)$. 


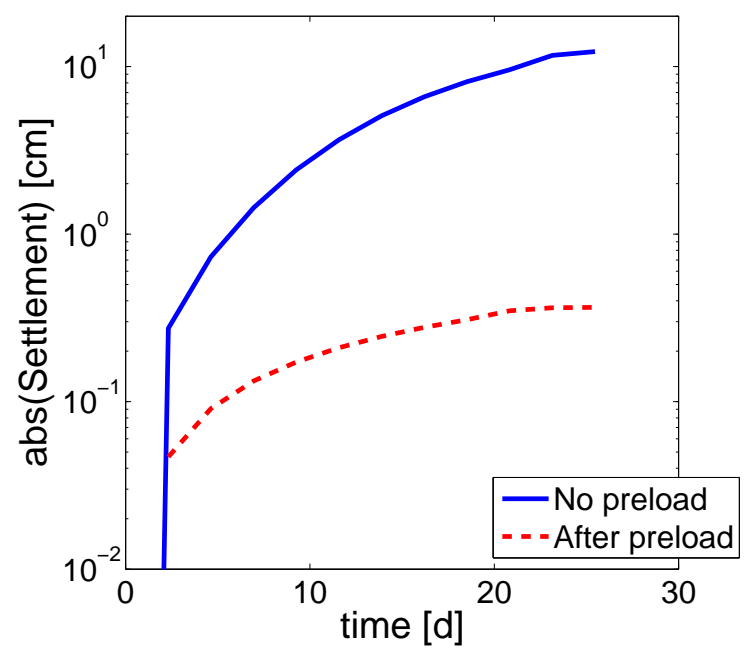

FIG. 12. Effect of preload on the settlement obtained during the construction of the road embankment. 


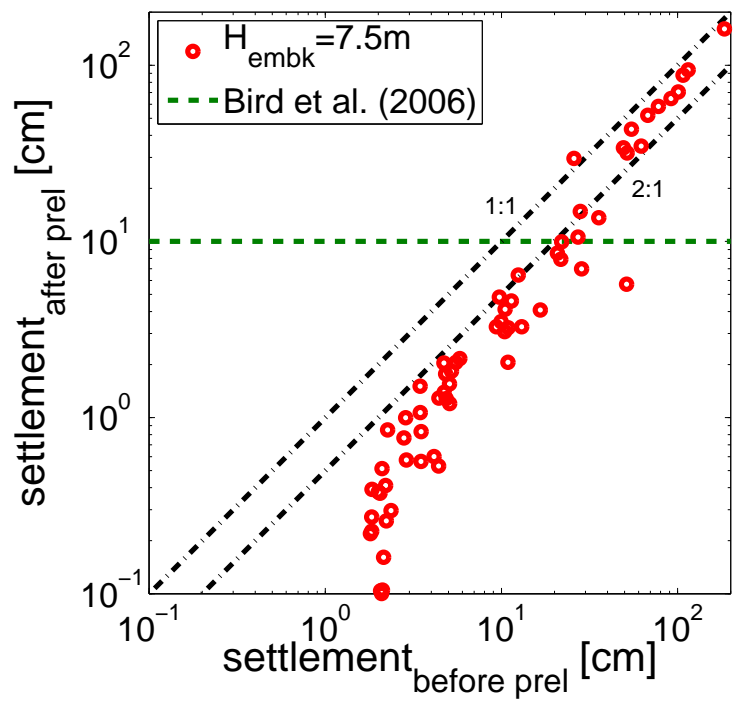

(a)

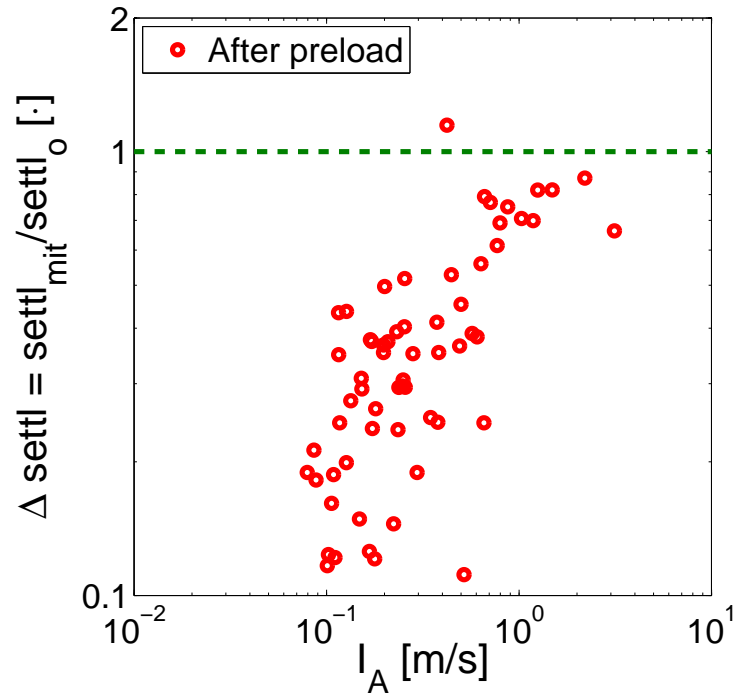

(b)

(a)

(b)

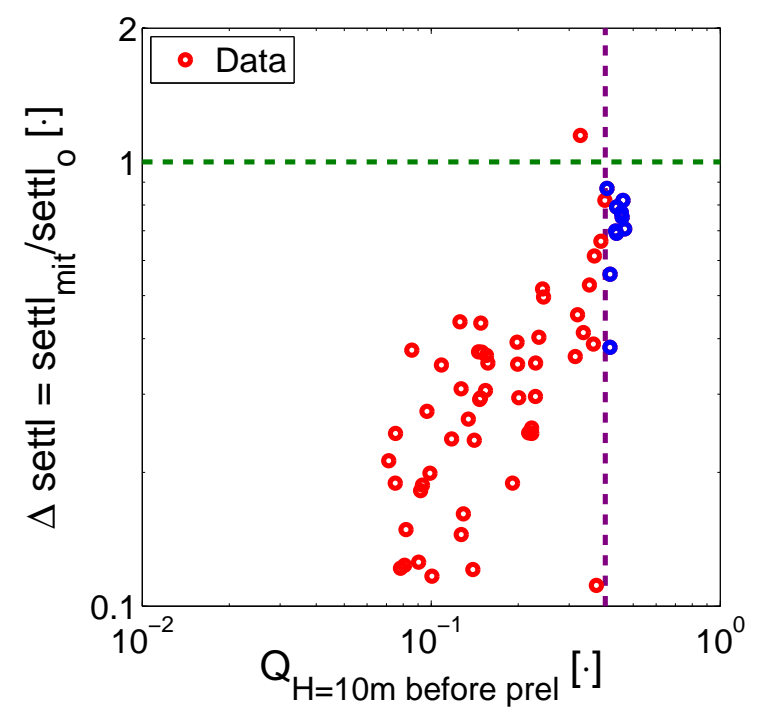

(c)

(c)

FIG. 13. Effect of preload embankment on the obtained a) co-seismic relative settlement values; b) Scatter plot of obtained $\Delta$ settl values as a function of $I_{A}$ and c) Scatter plot of obtained $\Delta$ settl values as a function of Liquefaction Index $\left(Q_{H}\right)$. 


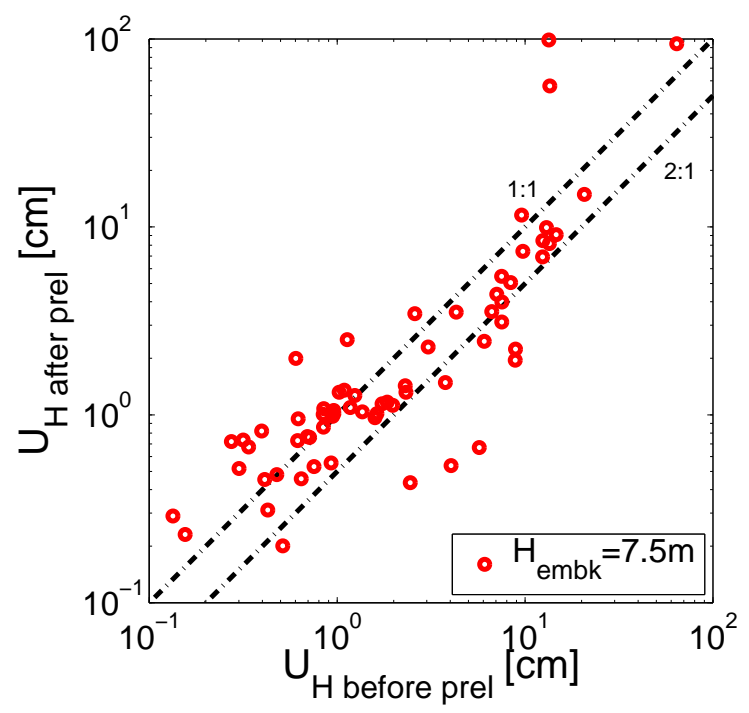

FIG. 14. Effect of preload embankment on the obtained co-seismic relative horizontal displacement values. 